\title{
Cytogenetic Study in Couples with Recurrent Miscarriage
}

\author{
*Tarek A. Atia, **Salah E. Mourad*** Salem H. \\ *Histology Dept., **Anatomy Dept., ***Gyn.\& Obst. Dept. \\ Al-Azhar Faculty of Medicine, Cairo, Egypt.
}

\begin{abstract}
:
Introduction: Recurrent miscarriage (RM) is a mysterious reproductive problem affecting a proportion of couples trying to conceive. Although spontaneous abortion occurs in approximately 15 to $20 \%$ of clinically diagnosed pregnancies of reproductive-aged women, recurrent miscarriage occurs in approximately 1 to $2 \%$ of these women. Many syndromes are involved in the aetiology of RM, where genetic factors appear to be highly associated. Indeed, chromosomal anomaly constitutes the single most common cause. About $7 \%$ of couples with RM have one partner with balanced chromosomal rearrangement.

Aim of the study: This study is a prospective study carried out to evaluate the incidence of chromosomal abnormalities in couples suffering recurrent miscarriage.

Patient and methods: The present study included one hundred couples attending the antenatal clinic. They have been divided into two groups; the first, is a study group, included 50 couples with recurrent miscarriage. And the second, is a control group, included 50 couples with normal reproductive history. Conventional cytogenetic analysis was done for both groups.

Result: We have found four cases (8\%) carrying chromosomal rearrangements (two reciprocal translocations, one Robertsonian translocation, and one with duplicated chromosome segment) among RM group, and no cases of chromosomal rearrangement among those with normal reproductive history. Statistically, there was a significant association between recurrent miscarriage and chromosomal rearrangement.

Conclusion: We have concluded that chromosome analysis is highly important to evaluate such cases with RM.
\end{abstract}

Key Words: Recurrent miscarriage, cytogenetics, chromosome anomalies.

\section{Introduction}

Human reproduction is an inefficient process, as $\sim 50 \%$ of all pregnancies were lost before the expected menses, and another $30 \%$ was lost after or around the time of a missed menses, i.e. before a woman realizes she is pregnant (Choudhury and Knapp. 2000). Miscarriages are considered any pregnancy loss before $20^{\text {th }}$ gestational weeks. Some authors further divide these into embryonic losses, which occur before the $9^{\text {th }}$ gestational week; and fetal losses, which occur at or after the $9^{\text {th }}$ gestational week to $20^{\text {th }}$ weeks (Kutteh, 2006). Recurrent miscarriage (RM) refers to three or more consecutive spontaneous abortions before the $20^{\text {th }}$ week of gestation. Spontaneous abortion represents 15-20\% among all clinically detectable pregnancies, but the incidence may be higher by adding the chemical detectable pregnancies (Ansari and Kirkpatrick, 1998). The actual prevalence of RM in all fertile couples of reproductive age is 1-2\% (Kutteh, 2006), and it is increased dramatically with maternal age $\geq 40$ years (Bulletti et al., 1996). Many studies showed a positive correlation between the number of previous miscarriages and the miscarriage rate in the next pregnancy, as up to $40 \%$ of women with three abortions and $50 \%$ of women with four abortions will expect foetal loss in their coming pregnancy (Quenby and Farquharson, 1993).

Many syndromes are known to be associated with RM such as anatomical anomalies, genetic disorders, hormonal 
disorders, immunological defects, infectious diseases and many other minor factors. Genetic disorders account for $\sim 25 \%$ of the known causes of RM (Ansari and Kirkpatrick. 1998). However, the prevalence could be higher as a fraction of unexplained causes may have genetic factors. Chromosomal abnormalities represent a great proportion of these genetic disorders. Moreover, research indicates other genetic defects that are not usually detected via routine investigation, but could affect the pregnancies outcome such as X-linked lethal traits (Lanasa et al., 1999), skewed $\mathrm{X}$-chromosome inactivation (Plenge et al., 2002), single gene defects (Hesse et al. 2000) and sperm chromosome abnormalities (Carrell et al., 2003).

Chromosomal anomalies are known to be the single most common cause of recurrent abortion, as 5-7\% of couples with RM have one partner with balanced chromosomal rearrangement mainly reciprocal translocations (Simpson and Bombard, 1987). Additionally, one of the most common causes of the first trimester abortion $(90 \%)$ is karyotypically abnormal pregnancies. Also, the majority (93\%) of karyotypically normal pregnancies continue (McFadyen, 1989).

Chromosomal disorders frequently seem sporadic; in most cases the partners' karyotype is normal, but during cell divisions after fertilization an error in segregation or recombination may occur. On the other hand, studies of in vitro fertilization (IVF) program have suggested that maternal non-disjunctions and premature centromere divisions (meiosis-1 errors) together with advanced maternal age resulting in oocyte aneuploidy. Also, oocytes associated with advanced maternal age show frequent meiotic spindle disorders and/or changes in chiasma resulting in increased incidence of non-disjunctions (McFadden and Friedman.1997).

The importance of such studies is to estimate the prevalence of chromosome anomalies among couples with RM. and to identify the treatable causes with reducing the chances of pregnancy failure. Also, it is helpful in introducing such women in the assisted fertilization program to improve their pregnancy outcome.

\section{Patients and Methods:}

A hundred couples attending outpatient clinic in Bab-Alsharia hospital (one of Al-Azhar University hospitals) have been included in this study. All couples have been explained the aim of this study and the steps of it. A formal consent has been taken from them. 50 couples (100 partners) who had experienced 3 or more successive miscarriages around the $12^{\text {th }}$ weeks of gestation, with natural ovarian cycles, and with all pregnancies fathered by the same partner were selected for this study. For this group, all results from a comprehensive recurrent pregnancy loss evaluation such as physical examination, hysterosalpingogram, thyroid function analysis, reproductive endocrine evaluation, lupus anticoagulant, anticardio-lipin antibody levels, and TORCH were within the normal ranges, and all apparent causes were excluded. The other 50 couples were with a normal reproductive history, and have at least one viable child; the control group was subjected for chromosome analysis. All cases were subjected for chromosome analysis using ordinary blood culturing and Giemsa-Trypsin G-banding ( $\sim 550$ band resolution) technique.

For routine cytogenetic analysis, 0.4 $\mathrm{ml}$ heparinized peripheral blood samples were incubated at $37^{\circ} \mathrm{C}$ for 72 hours in $10 \mathrm{ml}$ complete RPMI-1640 culture medium [100ml RPMI-1640 media supplemented with $1 \mathrm{ml}$ L-Glutamine, $20 \mathrm{ml}$ fetal calf serum, $1 \mathrm{ml}$ antibiotics (Penicillin-Streptomycin), and $2 \mathrm{ml}$ Phytohemagglutinin]. Cultured cells were harvested by adding $200 \mu \mathrm{l}$ colcemid for 20 minutes, followed by hypotonic $\mathrm{KCl}$ solution for 5 minutes and fixation using standard 3:1 methanol acetic acid fixative. Microscopic examination of 5-10 metaphases per case were done after standard Giemsa-Trypsin Gbanding staining technique. The chromosomes were analyzed microscopically; abnormalities were detected and two metaphases were captured per case. 


\section{Results:}

The frequencies of miscarriages in the current study ranged from 3 to 8 times. The maternal age in the RM group, at the time of investigation, ranged from 21 to 48 years with the mean of $33.7 \pm 1.943$ years. Where, $62 \%$ were above 35 years, and $32 \%$ were above 40 years. On the other hand, the maternal age of the control group ranged from 22 years to 43 years, with the mean of $32.6 \pm 1.564$ years. Hoever, $38 \%$ were above 35 years, and $12 \%$ were above 40 years (table 1).

In the present study we have found four cases $(8 \%)$, three females $(6 \%)$ and one male $(2 \%)$; with chromosomal rearrangements among couples suffering recurrent miscarriage. These included two cases with balanced reciprocal translocations, one case with Robertsonian translocations, and a case with duplicated chromosome segment (table 3). There was a more statistically significant chromosomal rearrangement in cases with recurrent miscarriage than cases with normal reproduction (table 2).

The first case; the female partner aged 44 years, had 8 previous abortions, and carries a Robertsonian translocation between chromosomes 13 and 14 and karyotyped as, 45,XX,der(13;14)(q10;q10), (Fig.1).

The second case; the male partner carries a reciprocal translocation between chromosomes 10 and 16, karyotyped as 46,XY,t(10;16)(q24;p13.1), (Fig.2). And his female partner aged 36 years and had 3 previous abortions.

The third case; the female partner aged 40 years, had 5 previous abortions, and carries a reciprocal translocation between chromosomes 11 and 22, and karyo-

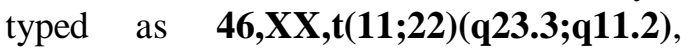
(Fig.3).

The fourth case; the female partner aged 28 years, had 3 previous abortions, and carries a duplicated segment of the long arm of chromosome 6 , and karyotyped as 46, $X X, \operatorname{dup}(6)(q 24.2 q 24.2)$, (Fig.4).

Table 1: Demographic data (maternal age and range of miscarriage in both groups.

\begin{tabular}{|l|l|l|}
\hline Parameters & Study group & Control group \\
\hline Maternal Age & $33.7( \pm 1.94)$ & $32.6( \pm 1.56)$ \\
\hline Range of miscarriage & $3-8($ median 4$)$ & $0-1(1)$ \\
\hline
\end{tabular}

Table 2: Correlation between recurrent miscarriage and chromosomal rearrangement. * statistically significant.

\begin{tabular}{|l|c|c|c|c|}
\hline Parameters & $\begin{array}{c}\text { Study group } \\
\mathrm{N}=50\end{array}$ & $\begin{array}{c}\text { Control group } \\
\mathrm{N}=50\end{array}$ & Chi square & P value \\
\hline $\begin{array}{l}\text { Chromosomal } \\
\text { rearrangement }\end{array}$ & $4(8 \%)$ & 0 & 4.1 & $<0.05^{*}$ \\
\hline
\end{tabular}

Table 3: Types of chromosomal rearrangement in cases with recurrent miscarriage.

\begin{tabular}{|l|c|c|c|l|}
\hline Case & $\begin{array}{c}\text { Maternal } \\
\text { Age }\end{array}$ & $\begin{array}{c}\text { Number of } \\
\text { full-term }\end{array}$ & $\begin{array}{c}\text { Number of } \\
\text { Abortion }\end{array}$ & \multicolumn{1}{|c|}{ Karyotyping } \\
\hline Case 1 & 44 & 0 & 8 & $45, X X, \operatorname{der}(13 ; 14)(\mathrm{q} 10 ; \mathrm{q} 10)$ \\
\hline Case 2 & 36 & 1 & 3 & $46, X Y, \mathrm{t}(10 ; 16)(\mathrm{q} 24 ; \mathrm{p} 13.1)$ \\
\hline Case 3 & 40 & 1 & 5 & $46, X X, \mathrm{t}(11 ; 22)(\mathrm{q} 23.3 ; \mathrm{q} 11.2)$ \\
\hline Case 4 & 28 & 1 & 3 & $46, \mathrm{XX}, \operatorname{dup}(6)(\mathrm{q} 24.2 ; \mathrm{q} 24.2)$ \\
\hline
\end{tabular}




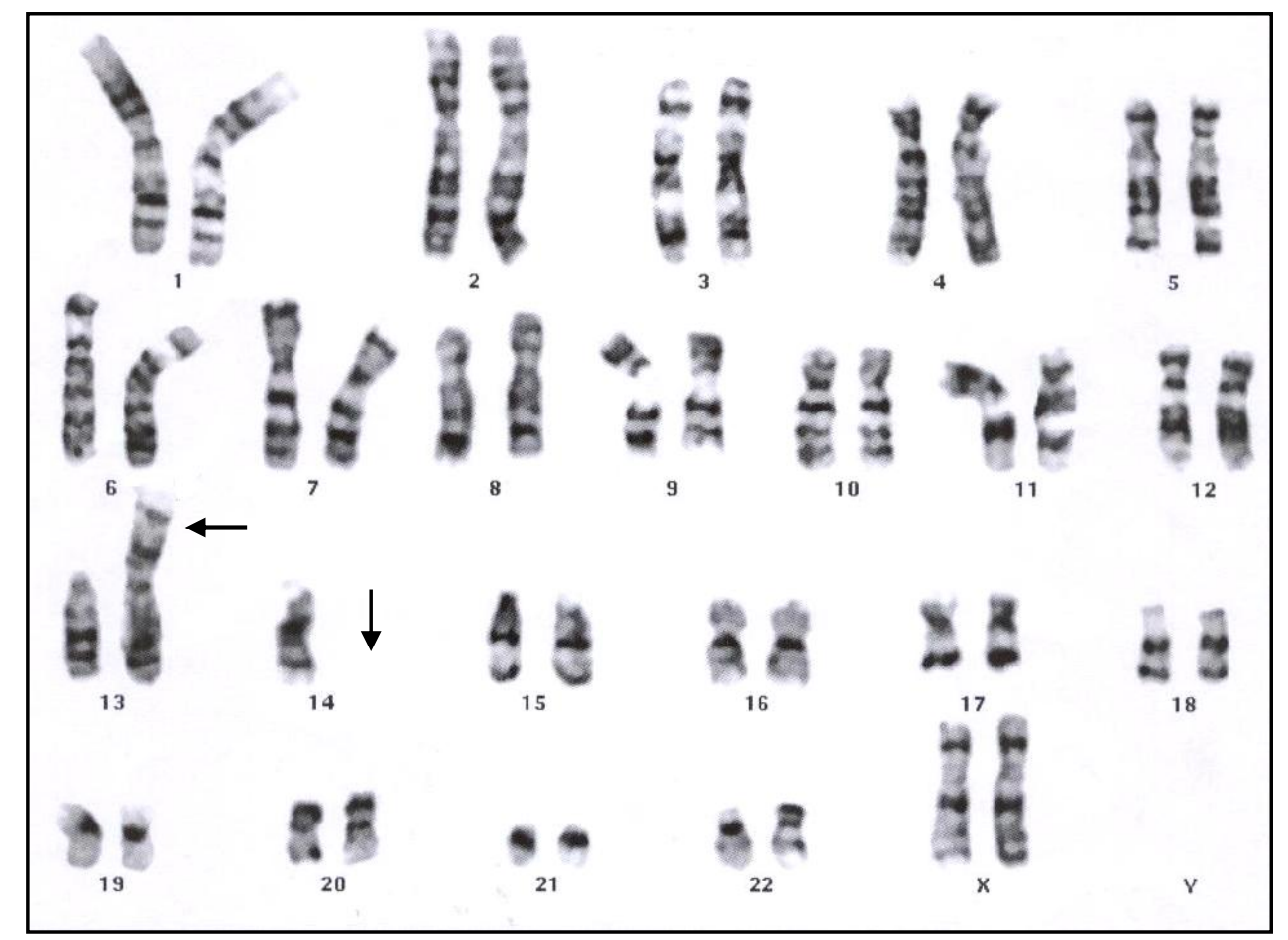

Fig. 1: Karyotyping of the first case, shows Robertsonian translocation between chromosomes 13 and 14 (arrows).

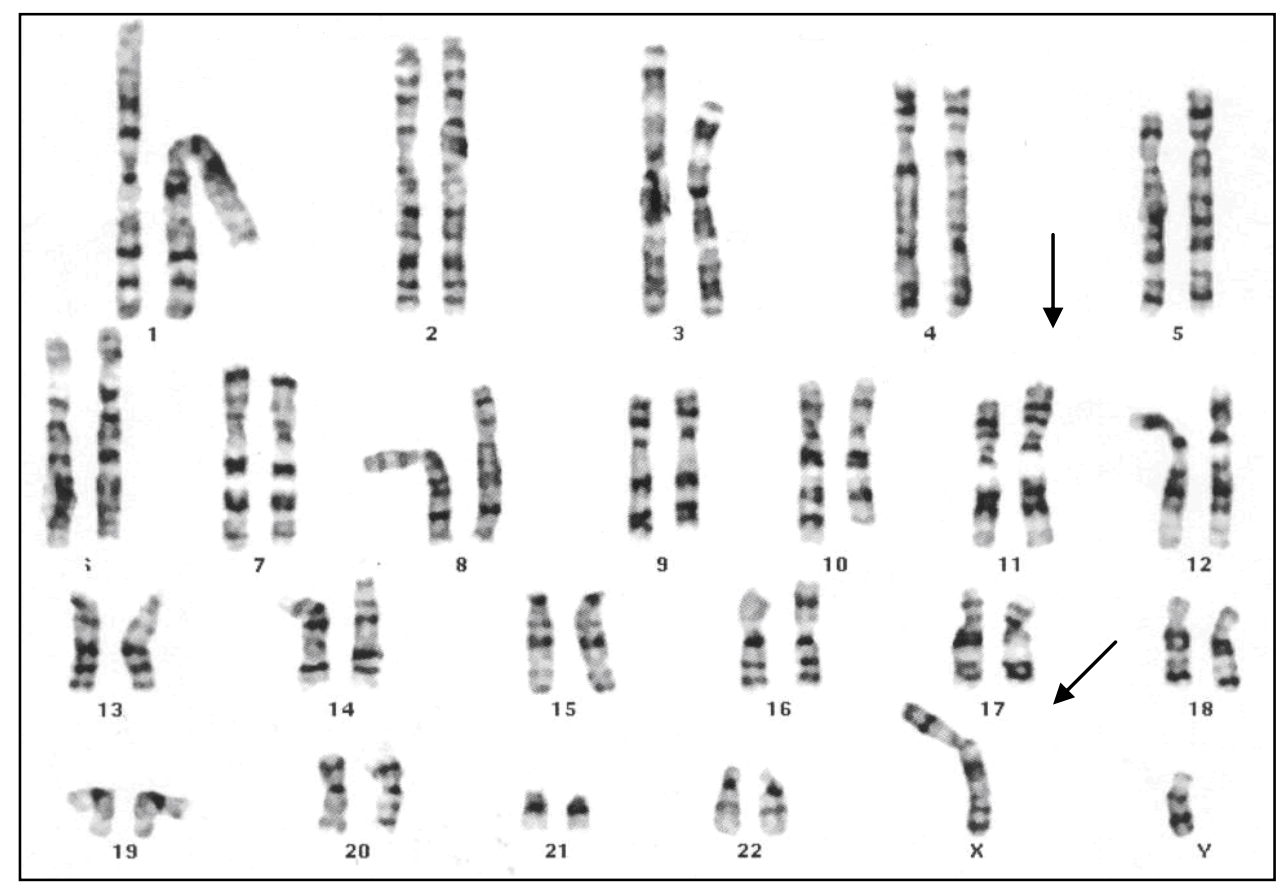

Fig. 2: Karyotyping of the second case, shows reciprocal translocation between chromosomes 10 and 16 (arrows). 


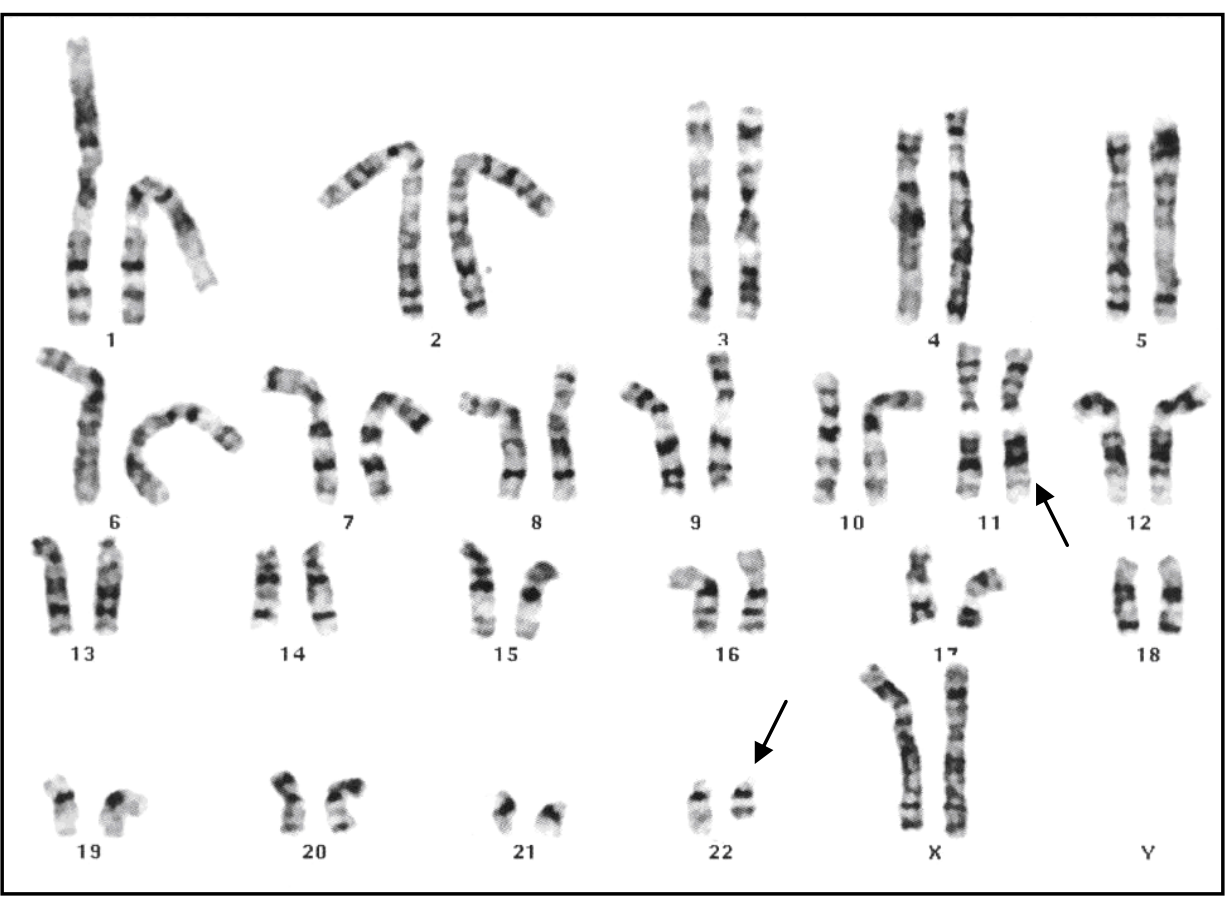

Fig. 3: Karyotyping of the third case, shows reciprocal translocation between chromosomes 11 and 22 (arrows).

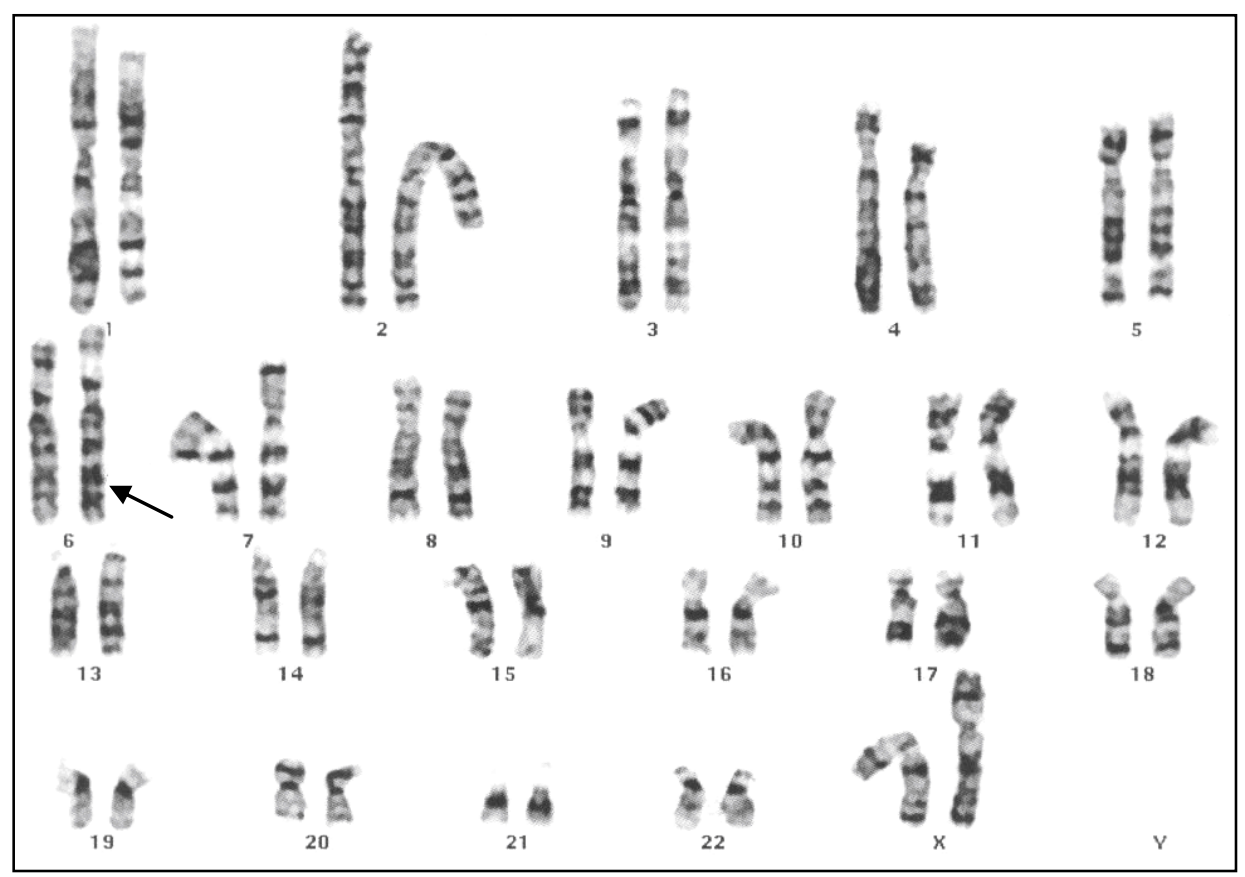

Fig. 4: Karyotyping of the third case, shows duplicated lower segment of chromosome 6 (arrow). 


\section{Discussion}

Recent data on recurrent miscarriage is discussed in the framework of the selection failure hypothesis which states, 'Recurrent miscarriage is the result of failure of the 'poor quality' embryos to implant, and represented clinically as recurrent miscarriage. Thus, recurrent miscarriage is a failure of nature's quality control' (Quenby et al., 2002). Failure of implantation and/or poor foeto-uterine interaction that caused by chromosomal and non-chromosomal factors, represents the main cause of miscarriage. Chromosomal analysis of abortus materials (between 8-15 weeks gestation) reveals an abnormal karyotype in $50-60 \%$ of cases; i.e. most embryonic chromosome anomalies are incompatible with life (Stephenson et al., 2002). In contrast, 5-7\% of couples with RM show abnormal karyotype; so the vast majority of foetal chromosome anomalies are de-novo, while the parent's karyotype is normal (Shaffer et al., 1996). Therefore, pre-fertilization factors (sperms and/or oocytes) or post-fertilization factors (mitotic and /or consequences of meiotic errors) might represent major problems that affect the foetal chromosome integrity.

Additionally, chromosomal anomaly in the outer trophoblast layer, which allows the embryo to be embedded in the uterus and forms the placenta and immunologic mechanism, appears frequently in cases of unexplained pregnancy loss (Clark. 1999). However, embryonic chromosome anomalies are almost always incompatible with life (Stephenson et al., 2002). Indeed , parental rather than foetal karyotyping is of clinical value for determining a chromosome abnormality with a recurrent risk of causing RM. The importance of foetal karyotyping in certain circumstances is to identify the cases which may be unable to obstetric treatment, as frequent euploid miscarried embryos are usually associated with other non-genetic causes (Carp et al., 2001).

In our study, the percentage of couples suffering from recurrent miscarriage and carrying chromosomal anomalies was $8 \%$. This rate was more statistically significant than cases without recurrent miscarriage $(\mathrm{P}<0.05)$. The $\mathrm{RM}$ percentage varies greatly according to the number of cases studied. For example, in a study performed by Al-Hussain and colleagues (2000) comparing the percentage of RM in different countries using variable case groups, they have found a great variety in that ratio. For example; in a French study using 217 couples, the ratio was $2.6 \%$; in a Japanese study using 639 couples, the ratio was $4.5 \%$; whereas in a Spanish study using 32 couples, the ratio was $17.8 \%$.

Secondly, $62 \%$ of female partners age was $\geq 35$ years, the age associated with increased incidence of meiotic nondisjunction, with increased abortion rate. Also, balanced translocation was commonly seen in our study (three out of four, in which two reciprocal and one Robertsonian translocation), and the minority (one case) carried imbalanced chromosomal rearrangement. Many authors mentioned that balanced translocations are commonly seen among couples suffering recurrent miscarriage (Dejmek et al. 1992; Al-Hussain et $a l$,. 2000), where the gene dosage is not affected by gain or loss, but just rearranged. Additionally, we have found a case with duplicated chromosome segment (imbalance rearrangement), i.e. gene dosage imbalance. The female partner was phenotypically normal while she gains a duplicated segment in the long arm of chromosome 6; thus this segment could contains no genes at all, few genes, or with gene dosage not critical. Such female carries abnormal chro-mosome in germline that could misseg-regate during meiosis leads to abnormal karyotyped fetus.

Several theories have been suggested to explain the mechanisms of nonhereditary chromosome anomalies that arise de novo during early embryo development. First, the double-strand DNA breaks (DSBs) and repair arise normally during DNA replication in meiosis. Multiple enzymes and proteins contribute to this process, so mutation/s of these proteins 
and/or enzymes could be lethal to cells or embryo (Brid and Kouzarides, 2000). Second, in higher eukaryotes, crossovers between homologous chromosomes are essential for proper disjunction of homologues during meiosis. Therefore, failures of performing DSBs, and/or DSB repairs can result in random disjunction of homologous chromosomes, and thus chromosome aneuploidy will result (Bascom-Slack et al., 1997). Taken together, multiple forms of chromosomal aberration could arise spontaneously in meiosis during foetal development, and could lead to recurrent foetal loss.

\section{Conclusion and recommendations:}

The causes of RM are variable and chromosomal aberration is the commonest cause. Several sporadic cases of RM have been noticed to carry chromosomal rearrangements, however large-scale studies by others and us revealed chromosome anomalies among the aetiology of RM. We recom-mend that all cases with recurrent miscarriage should be investigated for chromosomal aberration and those with chromosomal rearrangement may be counselled for assisted reproductive technology and preimplantation diagnosis.

\section{References}

1. Al Hussain M, Al-Nuaim L, Abu Talib Z, Osama $K$. and Zaki O K. (2000): Cytogenetic Study in Cases With Recurrent Abortion in Saudi Arabia. Ann Saudi Med., 20(3-4):233-236.

2. Ansari A H, and Kirkpatrick B. (1998): Recurrent pregnancy loss. The Journal of Reproductive Medicine, 43(9/s): 806-808.

3. Bascom-Slack $\mathbf{C}$ A, Ross $\mathbf{L} \mathbf{O}$, and Dawson D S. (1997): Chiasmata, crossovers, and meiotic chromosome segregation. Ad. Genetics, 35: 253-284.

4. Brid A, and Kouzarides T. (2000): Chromosomes and expression mechanisms. Current Opinion in Genetics and Development, 10: 141-143.

5. Bulletti C, Flamingi $\mathbf{C}$, and Giacomucci E. (1996): Reproductive failure duo to spontaneous abortion and recurrent miscarriage. Human Reproduction Update, 2(2): 118-136.

6. Carp H, Toder V, Aviram A, Daniely M, Mashiach S. and Barkai G. (2001): Karyotype of the abortus in recurrent miscarriage. Fertility and. Sterility, 75: 678-682.

7. Carrell D T, Wilcox A L, Lowy L, Peterson M, Jones K P, Erickson L, Campbell B, Branch W. and Hatasaka $H$ H. (2003): Elevated sperm chromosome aneuploidy and apoptosis in patients with unexplained recurrent pregnancy loss. Obstetrics \& Gynecology, 101 (6): 12291235

8. Choudhury S R. and Knapp L A. (2000): Human reproductive failure 1: Immunological factors. Human Reproduction Update, 7 (2): 113-134.

9. Clark D A. (1999): Ob-Gyn Case Challing. Critically examining the immunologic cases of recurrent miscarriage. Medscape Women's Health, 4 (3).

10. Dejmek J, Vojtassak J, and Malova J. (1992): Cytogenetic analysis of 1508 spontaneous abortions originating from south Slovakia. Eur. J. Obstet. Gynecol. Reprod. Biol., 46:129-36.

11. Hesse M, Franz T, Tamia Y, Takoto M M. and Magin T M. (2000): Targeted deletion of Keratins 18 and 19 leads to trophoblast fragility and early embryonic lethality. The EMBO journal, 19(19): 5060-5070.

12. Kutteh W H. (2006): Recurrent Pregnancy Loss. Seminar in Reproductive Medicine, 24(1): 3- 4 .

13. Lanasa M C, Hogge W A. and Hoffman E P. (1999): The X chromosome and recurrent spontaneous abortion: the significance of transmanifesting carriers. American J. Human. Genetics, 64: 934-938.

14. McFadden D E. and Friedman J M. (1997): Chromosome abnormalities in human beings. Mutation Res, 396: 192-140.

15. McFadyen I R. (1989) Early fetal loss. In Rodeck, C. (ed.) Fetal Medicine. Blackwell Scientific Publishers, Oxford., 26- 43.

16. Plenge $\mathbf{R}$ M, Stevenson $\mathbf{R} A$, Lubs $H A$, Schwartz C E, and Willard H F. (2002): Skewed X-chromosome inactivation is a common feature of $\mathrm{X}$-linked mental retardation disorders. Am. J. Human Genetics, 71(1): 168-73. 


\section{Cytogenetic Study in Couples with.}

17. Quenby S. and Farquharson R.

(1993): Predicting recurring miscarriage: What is important? Obstetric and Gynecology, 82: 132-138.

18. Quenby S, Vince G, Farquharson R. and Aplin J. (2002): Recurrent miscarriage: A defect in nature's quality control?. Human Reproduction, 17,(8): 1959-1963

19. Shaffer LG, Spik A S, Macha M. and Dunn R. (1996): Identification of a subtle chromosomal translocation in a family with recurrent miscarriage and a child with multiple congenital anomalies. Reproductive Med., 4(5): 367-371.

20. Simpson J L, and Bombard A. (1987): Chromosomal abnormalities in spontaneous abortion, pathology, and genetic counselling. In Benner,M.J. \& Edmond,D.K. (eds). Spontaneous and recurrent abortion .Oxford, Blackwell Scientific Publications: 51-76.

21. Stephenson M D, Aeatani $K \mathbf{A}$. and Robinson W P. (2002): Cytogenetic analysis of miscarriages from couples with recurrent miscarriage: a case study. Human Reproduction, 17(2): 446- 451. 


\section{دراسة الوراثة الخلوية للأزواج في حالات الإجهاض المتكرر}

طارق عبد الله عطية** _ صلاح الدسوقي عامر مراد*** ـ حسام الدين حسين كامل

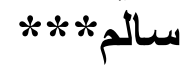

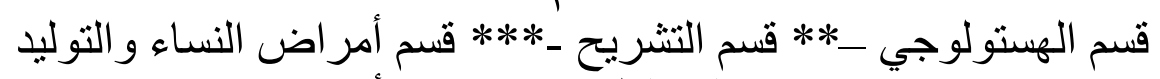
كلية الطب - جامعة الأز هر أنراتر

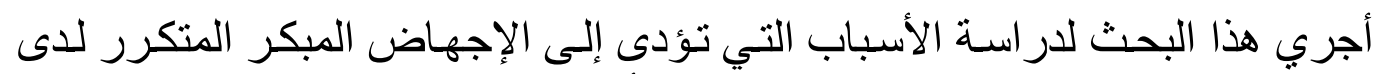

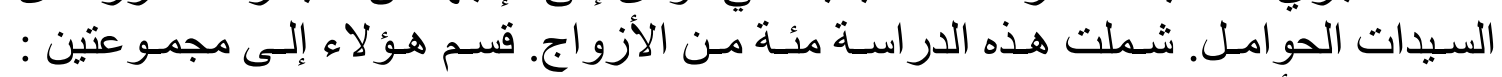

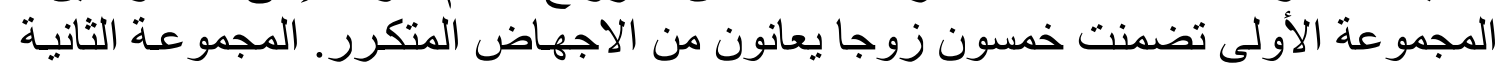

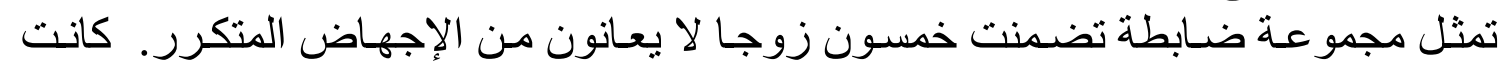

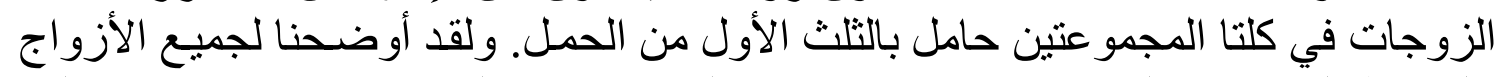

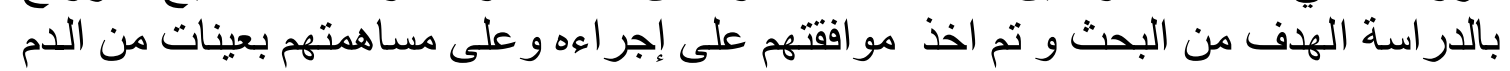

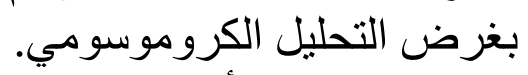

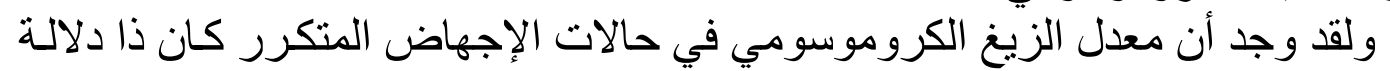

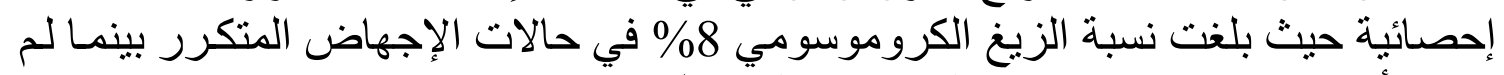

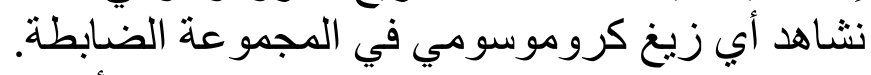

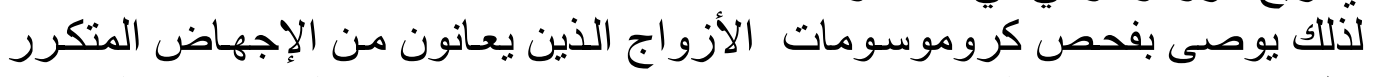

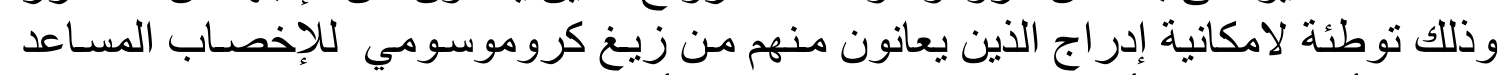

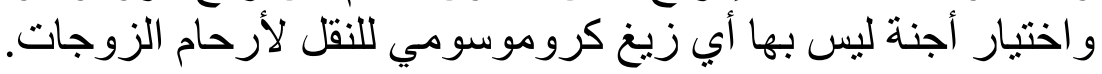

